$\xi=\square$

\title{
Identification of zingiber components by gas chromatograph/mass spectrometer and semi-empirical calculations
}

\author{
Mamoun S.M. Abd El-Kareem*, M.A.Rabbih, E.T.M.Selim \\ Molecular and atomic physics unit., Experimental Nuclear Physics Dept., Nuclear Research Centre, \\ Egyptian Atomic Energy Authority, Inshas, Cairo, Egypt \\ *Corresponding author_E-mail:mamoun_sarhan@yahoo.com
}

\begin{abstract}
The important used of Zingiber in different fields such as medicine and foods, this leads to study the physical and chemical properties of its components. The chemical components in Zingiber officinale Roscoe were identified by gas chromatograph/ mass spectrometer (GC/MS) with electron ionization mode. The major components of Zingiber under investigation namely: (1) Pentadecanoic acid (2) 1,3Dioxepane, 2-pentadecyl (3) 4H-Pyran-4-one, 2,3-dihydro-3,5-dihydroxy-6-methyl (4) gingerol. Electron ionization mass spectra of these compounds have been obtained and investigated. In addition, the semi-empirical (MNDO) method was used to calculate some physical and thermochemical properties for the structural of these compounds such as total energy, electronic energy, ionization energy, heats of formation, proton affinity and dipole moments which might to predict the activity and behavior of these compounds.
\end{abstract}

Keywords: Zingiber; Gas Chromatography-Mass Spectrometry and Semi-Empirical Calculations.

\section{Introduction}

Plants and leaves are as considered one of the main sources of biologically active compounds. Even today compounds from plants continue to play a major role in primary health care as therapeutic remedies in many developing countries [1].

Ginger (Zingiber officinale Rosc.) belongs to the family Zingiberaceae. It originated in South-East Asia and then used in many countries as a spice and condiment to add flavor to food [2]. Besides this, the rhizome of ginger has also been used in traditional herbal medicine. The health-promoting perspective of ginger is attributed to its rich phytochemistry.Ginger has staring potential for treating a number of ailments including degenerative disorders (arthritis and rheumatism), digestive health (indigestion, constipation and ulcer), cardiovascular disorders (atherosclerosis and hypertension), vomiting, diabetes mellitus, and cancer. It also has anti-inflammatory and anti-oxidative properties for controlling the process of aging. Furthermore, it has antimicrobial potentialas well which can help in treating infectious diseases [3-6].

GC-MS is a technique used for screening/identification/quantification of many susceptible compounds in plant extracts. Gas chromatography (GC) is used to separate all volatile components that might be present in the sample.The retention time (RT) is an identifying characteristic of these components. The detector for the GC is the mass spectrometer (MS). The fragmentation pattern for a component is unique and therefore is an identifying characteristic of a component. The identification of a component by its retention time (GC) and fragmentation pattern (MS), along with sample specific information afforded to make GC-MS the foremost confirmation method for analyzing herbal extract [7]. Up to date, gas chromatography-mass spectrometry (GC-MS) has played the most important role in the identification of the chemical composition of medical plants [8-10].
Many analytical methods including gas chromatograph coupled with mass spectrometer (GC/MS), high-performance liquid chromatography (HPLC), and its coupling to mass spectrometry (LC/MS), nuclear magnetic resonance (NMR), thin layer chromatography (TLC) and capillary electrophoresis (CE), have been used to characterize gingerol- related compounds in ginger[1116]. Among these methods, GC/MS has been used quite often to analyze ginger samples to predict the different components and its identification.

On the other hand, quantum chemical methods for the calculations of thermochemical data have developed beyond the level of just reproducing experimental data and can now make accurate predictions where the experimental data are unknown or uncertain [17] The semi-empirical molecular orbital (MO) methods of quantum chemistry [18-29] are widely used in computational studies of large molecules, particularly in organic chemistry and biochemistry. A great number of authors have been described the activity of the compounds using quantum chemical methods [30-35].

Much work have been done on Zingiber using GC-MS, LC-MS and many other analytical techniques as shown above. In the same time there have not found any work concern in quantum chemical calculations using semi-empirical (MNDO) method so far. So, the objective of the present work as follow:

1) Using GC-MS to identify the chemical composition record and investigate the mass spectra of Zingiber components by electron ionization mass spectrometry EI-MS.

2) Suggested the fragmentation pathways of the studied components, which was used to characterize the structures of these components.

3) Calculate and discussed some of thermochemical data physical properties of Zingiber components under investigation. The data present in this paper provided useful information on the different components of zingiber and can be used in the characterization of this important plant. 


\section{Materials and methods}

\subsection{Exteraction}

Dried roots of Zingiber officinale L. (ginger; Family Zingiberaceae) were obtained from a local Herbs and Medicinal Plants market (Alexandria, ARE). The plant was authenticated by staff members of the Botany Department, Faculty of Agriculture, Alexandria University, Alexandria, Egypt. The method used to extract the different components of zingiber is a new simple method. An aqueous extract was prepared by soaking $100 \mathrm{~g}$ of the dry ground ginger root in $500 \mathrm{ml}$ of distilled water at $40-50^{\circ} \mathrm{C}$ with daily shaking for 5 days; then, the extract was stored at $4^{\circ} \mathrm{C}$. The infusions were filtered through double-layered gauze, the filtrate was centrifuged at $3000 \mathrm{rpm}$ at $50{ }^{\circ} \mathrm{C}$ for $10 \mathrm{~min}$, and the water was evaporated in a hot air oven at $50^{\circ} \mathrm{C}$.

\subsection{GC-MS analysis}

GC-MS analysis was carried out on THERMO TRACE ULTRA GC coupled with THERMO ISQ (Gas Chromatograph-Mass Spectrometer instrument) employing the following conditions: column TG-5MS fused silica capillary column $(30 \mathrm{~m} \times 0.25 \mathrm{~mm} \times$ $0.25 \mu \mathrm{m}$ film thickness), operating in electron impact mode at $70 \mathrm{eV}$; Helium gas $(99.999 \%)$ was used as a carrier gas at a constant flow of $1 \mathrm{ml} / \mathrm{min}$ and an injection volume of $0.5 \mu \mathrm{I}$ was employed (split ratio of 10:1) injector temperature $250{ }^{\circ} \mathrm{C}$; ionsource temperature $280{ }^{\circ} \mathrm{C}$. The oven temperature was programmed from $110{ }^{\circ} \mathrm{C}$ (isothermal for $2 \mathrm{~min}$ ), with an increase of $10{ }^{\circ} \mathrm{C} / \mathrm{min}$, to $200^{\circ} \mathrm{C}$, then $5 \mathrm{oC} / \mathrm{min}$ to $280^{\circ} \mathrm{C}$, with hold $9 \mathrm{~min}$. Mass spectra of the four components recorded at $70 \mathrm{eV}$; scan interval time was 0.2 second and fragments from 40 to $450 \mathrm{Da}$. Total GC running time is $36 \mathrm{~min}$. $\mathrm{min}$.

\subsection{Identification of the components}

The components of Zingiber were identified by comparing their relative retention times and mass spectra with those of WILEY and NIST 05 mass spectral database. The spectrum of the unknown component was compared with the spectrum of the known component stored in the NIST and Wiley libraries. The retention time, molecular weight, molecular formula and composition percentage of the sample material were recorded and presented in Table 1.

\section{Results and discussion}

In Figure 1 Total Ion Chromatogram (TIC) measured for extracted Zingiber. The chemical composition of the studied components are listed in Table 1. The chemical structures with its mass spectra of the components are shown in Figures 2-5.

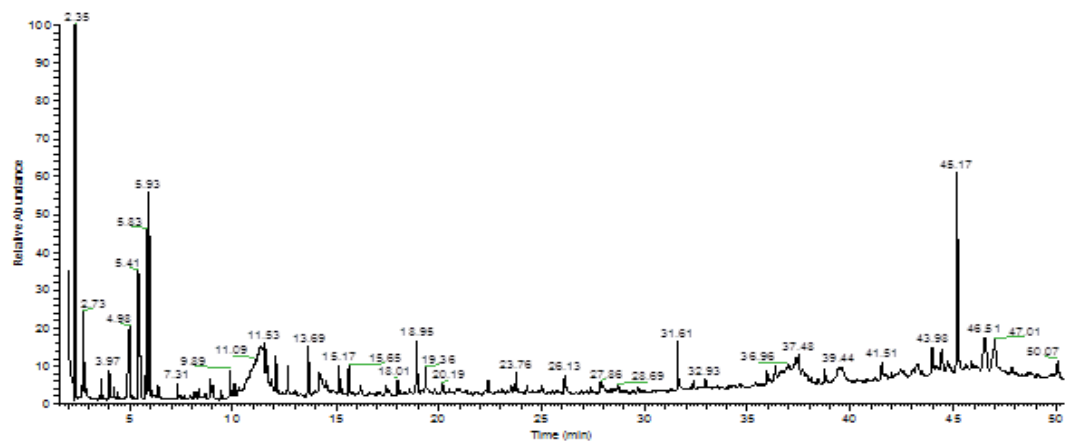

Fig. 1: Total Ion Chromatogram (TIC) Measured for Extracted Zingiber.

Table 1: The Chemical Composition of the Studied Components of Zingber

\begin{tabular}{lllll}
\hline No. & Rt. & Compound & $\begin{array}{l}\text { Molecular formula \& } \\
\text { Molecular weight }\end{array}$ & Compound nature and activity \\
\hline 1 & 11.41 & Pentadecanoic acid & $\mathrm{C}_{15} \mathrm{H}_{30} \mathrm{O}_{2}(\mathrm{MW}: 242)$ & $\mathrm{C}_{20} \mathrm{H}_{40} \mathrm{O}_{2}(\mathrm{MW}: 312)$ \\
2 & 12.69 & $\begin{array}{l}\text { 1,3-Dioxepane, 2-pentadecyl } \\
\text { 4H-Pyran-4-one, 2,3-dihydro-3,5-dihydroxy-6- } \\
\text { methyl }\end{array}$ & $\begin{array}{l}\mathrm{C}_{6} \mathrm{H}_{8} \mathrm{O}_{4}(\mathrm{MW}: 144) \\
\text { Bioactive compound have antiproliferative activity }\end{array}$ & $\begin{array}{l}\text { Flavonoid compound have anti- microbial and anti- } \\
\text { inflammatory effects. } \\
\text { Bioactive compound have an antipyretic, hypotensive, } \\
\text { cardiotonic,antiplatelet,antian-giogenic,anti- } \\
\text { inflammatory and analgesic, cytotoxic, apoptotic and } \\
\text { antitumor activities }\end{array}$ \\
\hline
\end{tabular}

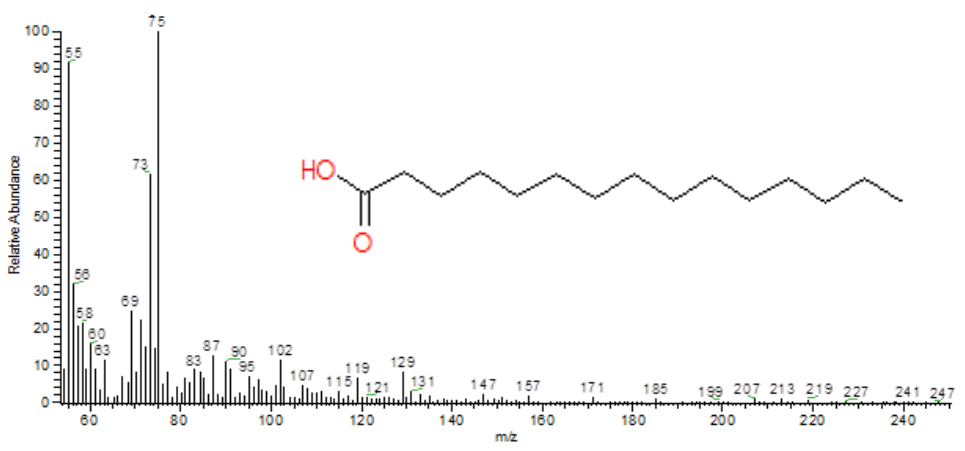

Fig. 2: The Mass Spectrum of Pentadecanoic Acid. 


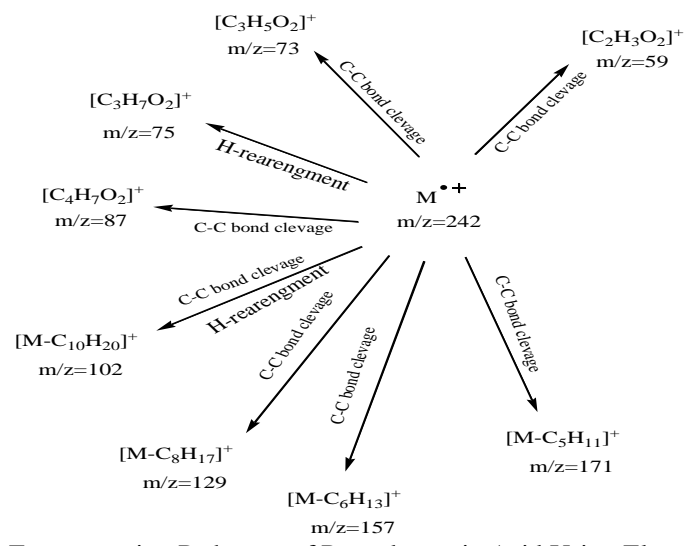

Scheme 1: Fragmentation Pathways of Pentadecanoic Acid Using Electron Ionization Technique.

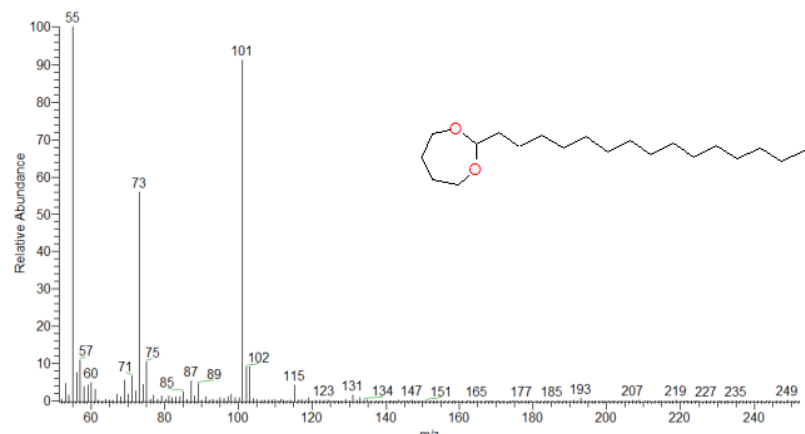

Fig. 3: The Mass Spectrum of 1, 3-Dioxepane, 2-Pentadecyl.

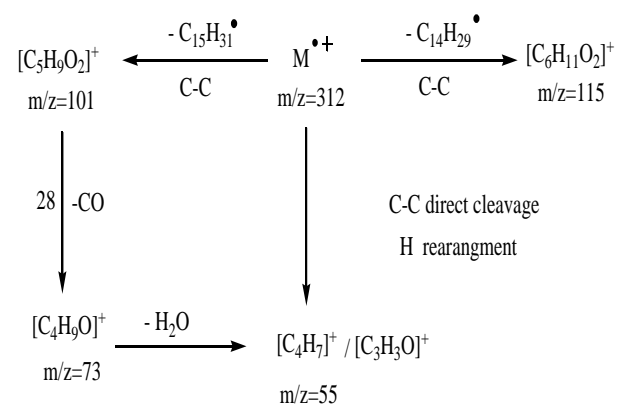

Scheme 2: Fragmentation Pathways of 1, 3-Dioxepane, 2-Pentadecyl Using Electron Ionization Technique.

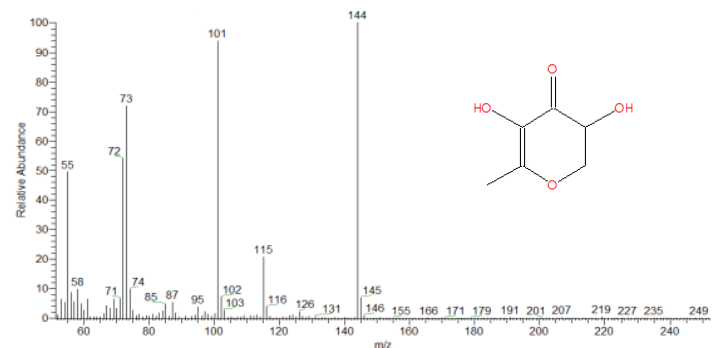

Fig. 4: The Mass Spectrum of 4H-Pyran-4-One, 2,3-Dihydro-3,5-Dihydroxy-6-Methyl.

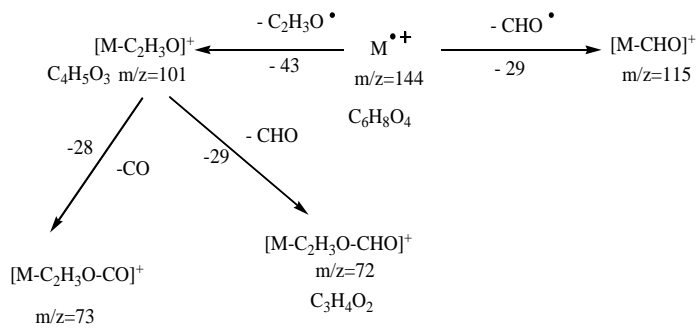

Scheme 3: Fragmentation Pathways of4h-Pyran-4-One, 2, 3-Dihydro-3, 5-Dihydroxy-6-Methylusing Electron Ionization Technique. 


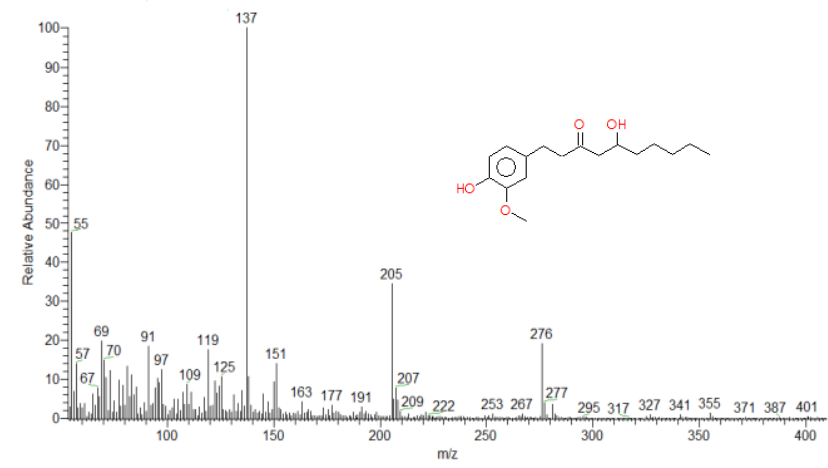

Fig. 5: The Mass Spectrum of Gingerol.

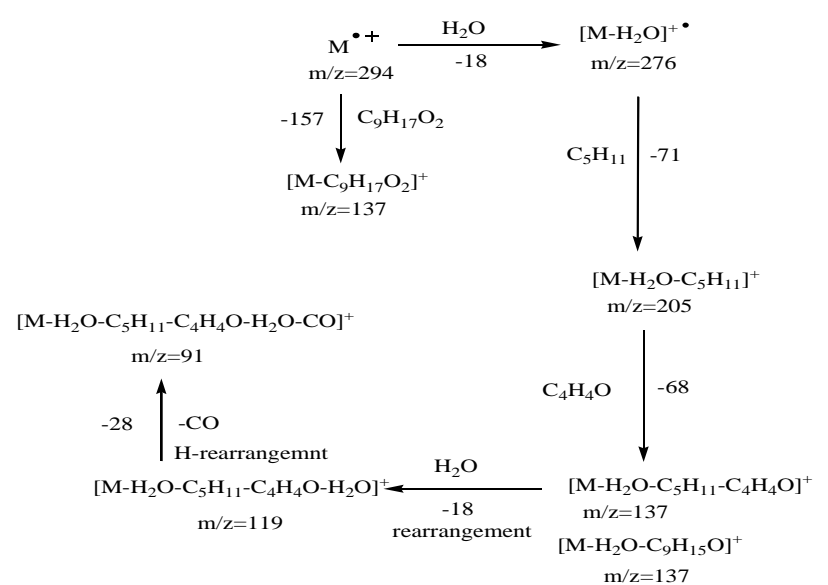

Scheme 4: Fragmentation Pathways of Gingerol Using Electron Ionization Technique.

\section{Structures investigation of the studied components mass spec-} tra:

The fragmentation pathways of the main fragment ions formed from molecular ions of the four studied compounds at $70 \mathrm{eV}$ are interpreted through fragmentation Schemes $1-4$.

1) The molecular ion of Pentadecanoic acid at $\mathrm{m} / \mathrm{z} 242$ has very low intensity in the EI mass this indicates that the molecular ion of this component thermally not stable. This molecular ion undergoes fragmentation by form $\left[\mathrm{C}_{2} \mathrm{H}_{3} \mathrm{O}_{2}\right]^{+}$, $\left[\mathrm{C}_{3} \mathrm{H}_{5} \mathrm{O}_{2}\right]^{+},\left[\mathrm{C}_{3} \mathrm{H}_{7} \mathrm{O}_{2}\right]^{+},\left[\mathrm{C}_{4} \mathrm{H}_{7} \mathrm{O}_{2}\right]^{+},\left[\mathrm{M}-\mathrm{C}_{8} \mathrm{H}_{17}\right]^{+}\left[\mathrm{M}-\mathrm{C}_{6} \mathrm{H}_{13}\right]^{+}$and $\left[\mathrm{M}-\mathrm{C}_{5} \mathrm{H}_{11}\right]^{+}$at $\mathrm{m} / \mathrm{z} 59,73,75,87,129,157$ and 171 respectively as shown in Scheme 1 .

2) The molecular ion of 1, 3-Dioxepane, 2-pentadecyl at $\mathrm{m} / \mathrm{z}$ $=312$ is not observed in the EI mass spectrum this indicates the molecular ion of this component thermally not stable. Also, the relative intensities of the ions, especially in the high mass region are generally low. The presence of the most intensities feature of the spectrum involves a formation of the base peak at $\mathrm{m} / \mathrm{z} 101$ having formation of form $\left(\mathrm{C}_{5} \mathrm{H}_{9} \mathrm{O}_{2}\right)^{+}$. The molecular ion of 1, 3-Dioxepane, 2pentadecyl undergoes fragmentation to form the fragment ion $\left[\mathrm{C}_{6} \mathrm{H}_{11} \mathrm{O}_{2}\right]^{+} \mathrm{m} / \mathrm{z} \quad 115$ and the fragment ion $\left[\mathrm{C}_{5} \mathrm{H}_{9} \mathrm{O}_{2}\right]^{+}$ $\mathrm{m} / \mathrm{z} 101$ which under fragmentation to form by loss of $\mathrm{CO}^{\circ}$ to form the fragment ion $\left[\mathrm{C}_{4} \mathrm{H}_{9} \mathrm{O}\right]^{+}$at $\mathrm{m} / \mathrm{z} 73$.

3) The molecular ion of 4H-Pyran-4-one, 2,3-dihydro-3,5dihydroxy-6-methyl at $\mathrm{m} / \mathrm{z} 144$ is observed in the EI mass spectrum which represents the base peak $(\mathrm{RI}=100 \%)$ in the mass spectrum this indicates that the molecular ion of this component have high stability. The first fragmentation pathway for 4H-Pyran-4-one, 2,3-dihydro-3,5-dihydroxy-6methyl is the formation of the fragment ion at $\mathrm{m} / \mathrm{z} 101$ which is certainly due to the ion $\left[\mathrm{M}-\mathrm{C}_{2} \mathrm{H}_{3} \mathrm{O}\right]^{+}$this fragment ion undergoes fragmentation by losing $\mathrm{CHO}$ and $\mathrm{CO}$ to form the ions $\left[\mathrm{M}-\mathrm{C}_{2} \mathrm{H}_{3} \mathrm{O}-\mathrm{CHO}\right]^{+}\left(\mathrm{m} / \mathrm{z}\right.$ 72) and $\left[\mathrm{M}-\mathrm{C}_{2} \mathrm{H}_{3} \mathrm{O}\right.$ $\mathrm{CO}^{+}(\mathrm{m} / \mathrm{z} 73)$, respectively. While the second fragmentation pathway is the formation of the fragment ion at $\mathrm{m} / \mathrm{z} 115$ which due to the loss of $\mathrm{CHO}^{\circ}$ to form the fragment ion [M$\mathrm{CHO}]^{+}$.
4) The molecular ion of gingerol at $\mathrm{m} / \mathrm{z}=294$ is not observed in the EI mass spectrum this indicates the molecular ion of this component thermally not stable. The first fragmentation pathway is the formation of the fragment ion at $\mathrm{m} / \mathrm{z} 276$ by loss $\mathrm{H}_{2} \mathrm{O}$ to form $\left[\mathrm{M}-\mathrm{H}_{2} \mathrm{O}\right]^{+}$ion with relative intensity $20 \%$ this fragment ion undergoes fragmentation by loss of $\mathrm{C} 5 \mathrm{H} 11$ radical to form the fragment ion $\left[\mathrm{M}-\mathrm{H}_{2} \mathrm{O}-\mathrm{C}_{5} \mathrm{H}_{11}\right]^{+}$at $\mathrm{m} / \mathrm{z}$ 205. This fragment ion represent the second peak with relative intensity $35 \%$ undergoes fragmentation by loss $\mathrm{C} 4 \mathrm{H} 4 \mathrm{O}$ to form the $\left[\mathrm{M}-\mathrm{H}_{2} \mathrm{O}-\mathrm{C}_{5} \mathrm{H}_{11}-\mathrm{C}_{4} \mathrm{H}_{4} \mathrm{O}\right]^{+}$at $\mathrm{m} / \mathrm{z} 137$ represent the base peak in gingerol mass spectrum which can produced from two processes $\left[\mathrm{M}-\mathrm{H}_{2} \mathrm{O}-\mathrm{C}_{5} \mathrm{H}_{11}\right]^{+}$then loss $\mathrm{C}_{4} \mathrm{H}_{4} \mathrm{O}$ and from the molecular ion by loss of $\mathrm{C}_{9} \mathrm{H}_{17} \mathrm{O}_{2}$ as shown in Scheme 4. Undergoes fragmentation by loss of $\mathrm{H}_{2} \mathrm{O}$ to form the fragment ion $\left[\mathrm{M}-\mathrm{H}_{2} \mathrm{O}-\mathrm{C}_{5} \mathrm{H}_{11}-\mathrm{C}_{4} \mathrm{H}_{4} \mathrm{O}-\mathrm{H}_{2} \mathrm{O}\right]^{+}$ at $\mathrm{m} / \mathrm{z} 119$ which also undergoes fragmentation by loss $\mathrm{CO}$ ion $\left[\mathrm{M}-\mathrm{H}_{2} \mathrm{O}-\mathrm{C}_{5} \mathrm{H}_{11}-\mathrm{C}_{4} \mathrm{H}_{4} \mathrm{O}-\mathrm{H}_{2} \mathrm{O}-\mathrm{CO}\right]^{+}$at $\mathrm{m} / \mathrm{z}$ 91. The second fragmentation process of the molecular ion of gingerol is the formation of the fragment ion $\left[\mathrm{M}-\mathrm{C}_{9} \mathrm{H}_{17} \mathrm{O}_{2}\right]^{+}$at $\mathrm{m} / \mathrm{z}$ 137 by loss of $\mathrm{C}_{9} \mathrm{H}_{17} \mathrm{O}_{2}$.

Semi-empirical molecular orbital calculations of the studied compounds:

Computational chemistry methods have been introduced that allow analysis of reaction mechanisms and prediction of the reactivity in synthetic chemistry. Therefore, computational chemistry used to predict the reactivates of a wide variety of organic molecules [36].

The optimized structures of the studied molecules shown in Table 2 using the MNDO method With HyperChem 7.5 program [37] for calculating the molecular properties of the studied molecules. Table 2. The values of these parameters like total energy, heats of formation, electronic energy, ionization energy, electron affinity and dipole moment of the studied molecules obtained using MNDO method at the ground and charged states while Table 3 show the proton affinities of the studied molecules at different oxygen atoms. 
Table 2: Values of Calculated Total Energy, Electronic Energy, Heats of Formations, Dipole Moment, Ionization Energy and Electron Affinity Using MNDO Method of the Studied Molecules.

\begin{tabular}{|c|c|c|c|c|}
\hline & Pentadecanoic acid & $\begin{array}{l}\text { 1,3-Dioxepane, 2- } \\
\text { pentadecyl }\end{array}$ & $\begin{array}{l}\text { 4H-Pyran-4-one, } \\
\text { 2,3dihydro-3,5-dihydroxy- } \\
\text { 6-methyl }\end{array}$ & Gingerol \\
\hline Total energy $\left(\mathrm{kcal} \mathrm{mol}^{-1}\right)$ & $\begin{array}{l}-68989(\mathrm{M}) \\
-68751(\mathrm{M})^{+1} \\
-68983(\mathrm{M})^{-1}\end{array}$ & $\begin{array}{l}-87005(\mathrm{M}) \\
-86805(\mathrm{M})^{+1} \\
-86992(\mathrm{M})^{-1}\end{array}$ & $\begin{array}{l}-50033(\mathrm{M}) \\
-49843(\mathrm{M})^{+1} \\
-50059(\mathrm{M})^{-1}\end{array}$ & $\begin{array}{l}-88379(\mathrm{M}) \\
-88184(\mathrm{M})^{+1} \\
-88390(\mathrm{M})^{-1}\end{array}$ \\
\hline Electronic energy $\left(\mathrm{kcal} \mathrm{mol}^{-1}\right)$ & $\begin{array}{l}-414628(\mathrm{M})- \\
414113(\mathrm{M})^{+1} \\
-414186(\mathrm{M})^{-1}\end{array}$ & $\begin{array}{l}-619308(\mathrm{M}) \\
-596999(\mathrm{M})^{+1} \\
-589254(\mathrm{M})^{-1}\end{array}$ & $\begin{array}{l}-216985(\mathrm{M}) \\
-217339(\mathrm{M})^{+1} \\
-216847(\mathrm{M})^{-1}\end{array}$ & $\begin{array}{l}-587706(\mathrm{M}) \\
-578744(\mathrm{M})^{+1} \\
-582991(\mathrm{M})^{-1}\end{array}$ \\
\hline Heats of formation $\Delta H_{\mathrm{f}}(\mathrm{M})\left(\mathrm{kcal} \mathrm{mol}^{-1}\right)$ & -162 & -163 & -161 & -183 \\
\hline Heats of formation $\Delta \mathrm{H}_{\mathrm{f}}(\mathrm{M})^{+\bullet}\left(\mathrm{kcal} \mathrm{mol}^{-1}\right)$ & 74 & 37 & 29 & 15 \\
\hline Heats of formation $\Delta \mathrm{H}_{\mathrm{f}}(\mathrm{M})^{-1}\left(\mathrm{kcal} \mathrm{mol}^{-1}\right)$ & -158 & -150 & -188 & -192 \\
\hline Dipole moment (D) & 1.64 & 1.14 & 1.53 & 4.96 \\
\hline Ionization energy (eV) & 10.2 & 8.7 & 8.2 & 8.5 \\
\hline Electron affinity $(\mathrm{eV})$ & -0.17 & -0.60 & 1.17 & 0.40 \\
\hline
\end{tabular}

Table 3: Calculated Heats of Formation Values for Protonated Molecules $\Delta \mathrm{H}_{\mathrm{f}}(\mathrm{M}+\mathrm{H})^{+}$and Proton Affinities (PA) at Different Oxygen Atoms Sites Using MNDO Method.

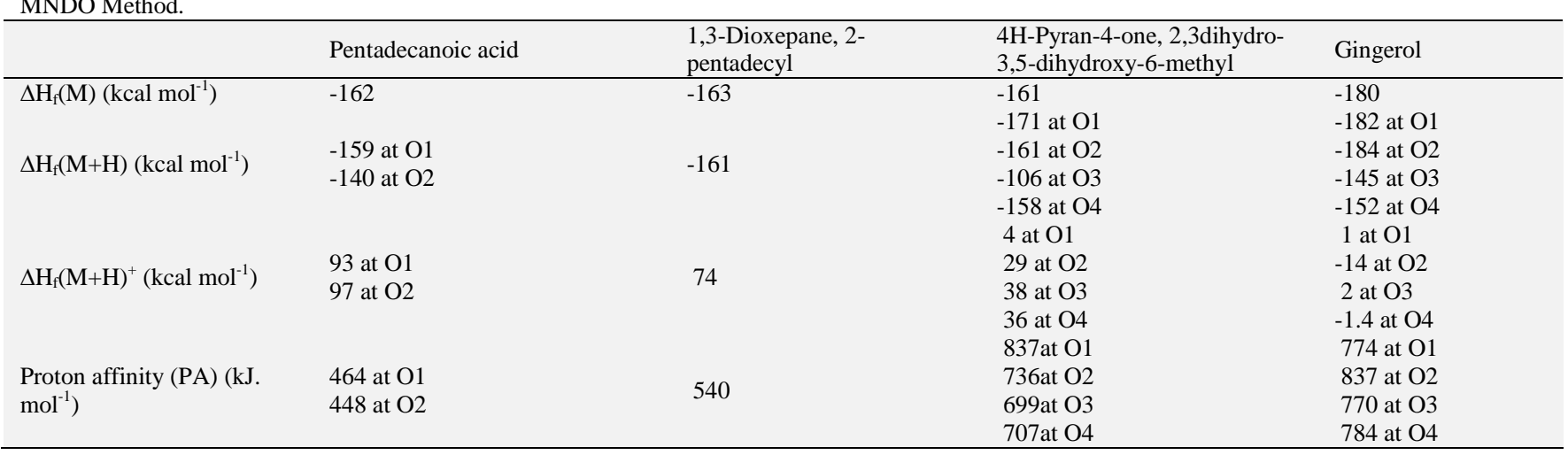

It is interesting to calculate the physical parameters such as total energy, electronic energy, dipole moment and thermochemical quantities such as heats of formation $\Delta H_{f}(M), \Delta H_{f}(M)^{-1}$ and $\Delta \mathrm{H}_{\mathrm{f}}(\mathrm{M})^{+\bullet}$ for the studied molecules using the MNDO method. Hence, one can calculate the IE value for these molecules as the difference between $\Delta \mathrm{H}_{\mathrm{f}}(\mathrm{M})^{+\bullet}$ and $\Delta \mathrm{H}_{\mathrm{f}}(\mathrm{M})$ and the electron affinity as the difference between total energies at neutral $(\mathrm{M})$ and anion $(\mathrm{M})^{-1}$ states.

From the calculated data reported in Table 1, one can note that, the heats of formation of the molecules (1) Pentadecanoic acid (2) 1,3-Dioxepane, 2-pentadecyl and (3) 4H-Pyran-4-one, 2,3dihydro3,5-dihydroxy-6-methyl at the neutral state are approximately have the same values $(-162,-163$ and $-161 \mathrm{kcal} / \mathrm{mol})$ respectively while the heats of formation of Gingerol molecule is -183 $\mathrm{kcal} / \mathrm{mol}$. These negative values of the heats of formation for the four molecules indicate their stability while for gingerol compound which has the highest one in stability as shown in Table 1. This conformed by the total ion chromatogram, hence gingerol represent the major compound and have the more intense peak as shown in fig.1.

Ionization potential and dipole moment are one of the main characteristics of atoms or molecules. They rely heavily on nature and strength of intermolecular bonds and chemical bonds in molecules [36]. The calculated values of ionization energy of the Pentadecanoic acid, 1, 3-Dioxepane, 2-pentadecyl: 4H-Pyran-4-one, 2, 3dihydro-3, 5-dihydroxy-6-methyl and gingerol molecules are $10.2,8.7,8.2$ and $8.5 \mathrm{eV}$ as shown as in Table 1 . are approximately have the same value except Pentadecanoic acid have ionization energy value equal to $10.2 \mathrm{eV}$ as reported in Table 1.

The dipole moment for (1) Pentadecanoic acid (2) 1,3-Dioxepane, 2-pentadecyl (3) 4H-Pyran-4-one, 2,3dihydro-3,5-dihydroxy-6methyl at the neutral state are approximately have the same values $(1.643,1.141$ and $1.534 \mathrm{D})$ respectively. This means that they have the same molecular polarity while gingerol molecule has the highest value of the dipole moment which equal to $4.96 \mathrm{D}$ this means that, gingerol has highest molecular polarity. As shown in Table 1.
Proton affinities and heats of formation are important thermodynamic quantities that can be derived from a variety of experimental measurements. Modern composite computational methods provide the means to reliably estimate the same quantities with an accuracy that often rivals that of experiment [38]. In addition, these methods can provide information to complement results obtained experimentally and to examine problems that are not easily approached directly, such as site-specific proton affinities [38]. A case in point is the protonation of the molecules, which often can take place at more than one position. In principle, the protonation of these compounds may be protonated at the hetero atoms (oxygen atoms in these compounds). The most negative atoms in the four compounds are localized on oxygen atoms. The calculated data reported in Table 2. For the studied molecules have been done using MNDO method at different positions of oxygen atoms of the optimized structures Figure 6.

From the calculated thermochemical data of the studied molecules, one can note that the proton affinity for Pentadecanoic acid molecule at the site $(\mathrm{O} 1-\mathrm{H})$ is $464 \mathrm{~kJ}^{-\mathrm{mol}^{-1}}$ and $(\mathrm{O} 2-\mathrm{H})$ is 448 $\mathrm{kJ} \mathrm{mol}^{-1}$. The proton affinity at the site $(\mathrm{O} 2-\mathrm{H})$ is less than the value at $(\mathrm{O} 1-\mathrm{H})$ site by $16 \mathrm{~kJ}^{\mathrm{mol}}{ }^{-1}$ The calculated values of the proton affinity of 1,3-Dioxepane, 2-pentadecyl molecule at the two positions $\mathrm{O} 1$ and $\mathrm{O} 2$ have equal values $540 \mathrm{~kJ}^{\mathrm{mol}} \mathrm{mol}^{-1}$. This due to the symmetry of the two Oxygen atoms positions.

4H-Pyran-4-one,2,3dihydro-3,5-dihydroxy-6-methyl molecule have four proton affinity positions, the most stable position is at $(\mathrm{O} 1-\mathrm{H})$ since have the highest proton affinity $\left(837 \mathrm{~kJ}^{\left.-\mathrm{mol}^{-1}\right)}\right.$ value than other three positions. This due to the carbonyl $\mathrm{C}=\mathrm{O}$ group.

Finally, the gingerol molecule have four proton affinity positions, the most stable position is at $(\mathrm{O} 2-\mathrm{H})$ since have the highest pro-

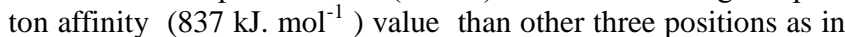
Table 2.

From the above discussion of the proton affinity, one can note that, 4H-Pyran-4-one,2,3dihydro-3,5-dihydroxy-6-methyl and gingerol compounds have the highest proton affinity value $837 \mathrm{~kJ}$. $\left.\mathrm{mol}^{-1}\right)$ at $(\mathrm{O} 1-\mathrm{H})$ and $(\mathrm{O} 2-\mathrm{H})$, respectively. The protonation at 
carbonyl group is favored which consider as the more stable site of protonation in all studied molecules. Also, One can note that the most two stable protonation sites are occur at the double bond oxygen atom $\mathrm{C}=\mathrm{O}$. This means that, these sites are active side bond for biological activity of gingerol and 4H-Pyran-4one,2,3dihydro-3,5-dihydroxy-6-methyl. This confirmed also by previous corresponding author Phd thesis [39].

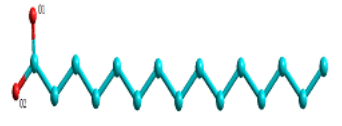

(1)

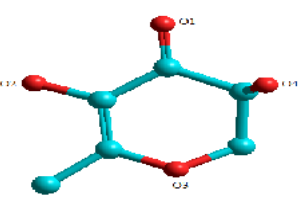

(3)
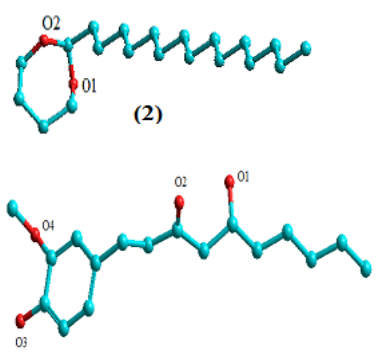

(4)
Figure 6. The different protonation positions of optimized structures of the studied molecules (1-4)

\section{Conclusions}

The experimental investigations show that the application of GCMS can provide a rather detailed analysis of Zingiber Components by using the obtained chromatogram and mass spectra. The mass spectra of the studied components have been recorded and investigated, and the fragmentation mechanisms pathways have been suggested and discussed. The experimental data together with the theoretical quantum chemical calculations MNDO give us more information about the chemical behavior of the studied molecules which may be important for many chemical and medical applications. So MNDO method have been used to calculated these thermochemical and physical properties of the studied components and correlate these data with experimental part to understanding the chemical behavior of the studied compounds (these data are clear in Table2-3 and a. section).

\section{References}

[1] Bobbarala V, Bramhachari PV, Ravichand J, Reddy YHK, Kotresha D, Chaitanya KV (2011), J Pharm Res 4(1): 252-255.

[2] Park EJ, Pizzuto JM (2002), Botanicals in cancer chemoprevention. Cancer Metast Rev. 21:231-55 http://dx.doi.org/10.1023/A:1021254725842.

[3] Shukla Y, Singh M (2007), Cancer preventive properties of ginger: A brief review. Food Chem Toxicol.45:683-90. http://dx.doi.org/10.1016/j.fct.2006.11.002.

[4] Jiang H, Xie Z, Koo HJ, McLaughlin SP, Timmermann BN, Gang DR (2006), metabolic profiling and phylogenetic analysis of medicinal Zingiber species: Tools for authentication of ginger (Zingiber officinale Rosc.) Phytochemistry. 67:232-44. http://dx.doi.org/10.1016/j.phytochem.2005.08.001.

[5] Ali BH, Blunden G, Tanira MO, Nemmar A (2008), some phytochemical, pharmacological and toxicological properties of ginger (Zingiber officinale Roscoe): A review of recent research. Food Chem http://dx.doi.org/10.1016/j.fct.2007.09.085.

[6] Nicoll R, Henein MY (2009), Ginger (Zingiber officinale Roscoe): A hot remedy for cardiovascular disease. Int. J. Cardiol. 131:408-9. http://dx.doi.org/10.1016/j.ijcard.2007.07.107.

[7] K. Mythili, C. Umamaheswara Reddy, D. Chamundeeswari, P.K Manna(2013), GC-MS analysis of phytocomponents and in-vitro inhibitory effects ofCalanthe triplicata. Journal of Natural Products, 6:141-146)

[8] V. Lakshmi and G. Viji Stella Bai (2015), Determination of Biologically active compounds in Clerodendrum phlomidis (L.) leaf extract using GC/MS. International Journal of Multidisciplinary Research and Development. 2(1): 294-300.
[9] Jeena K1, Liju VB, Kuttan R(2013), Antioxidant, antiinflammatory and antinociceptive activities of essential oil from ginger.Indian Journal of Physiology and Pharmacology. 57(1):5162.

[10] Omnia Ismail Mohamed, Abeer Fekry El-Nahas, Yasser Said ElSayed \& Khaled Mohamed Ashry.(2015). Ginger extract modulates $\mathrm{Pb}$-induced hepatic oxidative stress and expression of antioxidant gene transcripts in rat liver .Pharm Biol, Early Online: 1-9 http://dx.doi.org/10.3109/13880209.2015.1057651.

[11] Catchpole OJ, Grey JB, Perry NB, Burgess EJ, Redmond WA, Porter NG (2003), Extraction of chili, black pepper, and ginger with near-critical $\mathrm{CO} 2$, propane, and dimethyl ether: analysis of the extracts by quantitative nuclear magnetic resonance.Journal of Agricultural and Food Chemistry. 51: 4853. http://dx.doi.org/10.1021/jf0301246.

[12] Connell DW, McLachlan R. J. D.W. Connell, R(1972), Journal of Chromatography A, 67( 1),29-35 http://dx.doi.org/10.1016/S00219673(01)97144-4.

[13] He X, Bernart M, Lian L, Lin L (1998),High-performance liquid chromatography-electrospray mass spectrometric analysis of pungent constituents of ginger. Journal of Chromatography A, 796, 2,327-334. http://dx.doi.org/10.1016/S0021-9673(97)01013-3.

[14] Huang H, Kuo K, Hsieh Y(1997), Determination of cinnamaldehyde, cinnamic acid, paeoniflorin, glycyrrhizin and [6]-gingerol in the traditional Chinese medicinal preparation Kuei-chih-tang by cyclodextrin-modified micellar electrokinetic chromatography. J. Chromatogr. A, 771, 267-274. http://dx.doi.org/10.1016/S00219673(97)00136-2.

[15] Jolad S, Lantz R, Solyom A, Chen G, Bates R, Timmermann $\mathrm{B}$ (2004), Fresh organically grown ginger (Zingiber officinale): composition and effects on LPS-induced PGE2production. Phytochemistry. 65: 1937-1954. http://dx.doi.org/10.1016/j.phytochem.2004.06.008

[16] S.S. Choudhari, B.M. Kareppa(2013), Identification of bioactive compounds of Zingiber Officinale Roscoe Rhizomes through gas chromatography and mass spectrometry . International Journal of Pharmaceutical Research \& Development, 5(08), $16-20$.

[17] A.C.Larry and R.Krishnan; (1998), "Computational Thermochemistry Prediction and Estimation of Molecular Thermodynamics",(Eds. K.I.Karl and D.J.Frurip), American Chemical Society, pp. 176.

[18] M.J.S. Dewar (1969), "The molecular Orbital Theory of Organic Chemistry", McGrawHill: New York, NY.

[19] D.L.Pople and J.A.Beveridge(1970), "Approximate Molecular Orbital Theory", Mc Graw-Hill, New York,NY.

[20] J.N.Murrell and A.J.Harget (1972), "Semiempirical SelfConsistent-Field Molecular Orbital Theory of Molecules", Wiley,New York,NY.

[21] G.A.Segal(1977), "Modern Theoritcal Chemistry"; Plenum: New York,NY, 7-8.

[22] Dewar, M.J.S. (1975) Quantum Organic Chemistry. Science, 187, 1037-1044. http://dx.doi.org/10.1126/science.187.4181.1037.

[23] Jug, K. (1980). Quantum Chemical Methods and Their Applications to Chemical Reactions. Theoretica Chimica Acta, 54, 263-300. http://dx.doi.org/10.1007/BF00552463.

[24] Dewar, M.J.S. (1985) Applications of Quantum Mechanical Molecular Models to Chemical Problems. Part 70. Quantum Mechanical Molecular Models. The Journal of Physical Chemistry, 89, 2145-2150. http://dx.doi.org/10.1021/j100257a004.

[25] Thiel, W. (1988), Semiempirical Methods: Current Status and Perspectives. Tetrahedron, 44, 7393-7408. http://dx.doi.org/10.1016/S0040-4020(01)86235-9.

[26] Stewart, J.J.P. (1990), MOPAC: A Semiempirical Molecular Orbital Program. Journal of Computer-Aided Molecular Design, 4, 1 103. http://dx.doi.org/10.1007/BF00128336.

[27] J.J.P.Stewart (1991), "Reviews in Computational Chemistry",(Eds. K.B.Lipkowitz and D.B.Boyd),VCH Publishers, New York,NY,1, pp. 45 .

[28] M.C.Zamer; "Reviews in Computational Chemistry",(Eds. K.B.Lipkowitz and D.B.Boyd), VCH Publishers; New York,NY, 2, pp.313,(1990)

[29] W.Thiel; "Advances in Chemical Physics: New Methods in Computational Quntum Mechanics", (Eds. I.Prigogine and A.R.Stuart), 93, 703, (1996).

[30] Luciana A. Fernandez, Marisa R. Santo , Mario Reta, Liliana Giacomelli, Rosa Cattana, Juana J. Silber, Mariela Risso, Hugo Cerecetto , Mercedes Gonzalez and Claudio Olea-Azar. Relationship between Physicochemical Properties and Herbicidal Activity of 1, 2, 5-Oxadiazole N-Oxide Derivatives. Molecules 2005, 10(9), 1197 1208; http://dx.doi.org/10.3390/10091197. 
[31] Saskia A. B. E. van Acker, Marcel J. de Groot, Dirk-Jan van den Berg, Michèl N. J. L. Tromp, Gabrielle Donné-Op den Kelder, Wim J. F. van der Vijgh, and Aalt Bast. A Quantum Chemical Explanation of the Antioxidant Activity of Flavonoids. Chemical Research in Toxicology, 1996, 9 (8), pp 1305-1312. http://dx.doi.org/10.1021/tx9600964.

[32] El Hassane Anouar. A Quantum Chemical and Statistical Study of Phenolic Schiff Bases with Antioxidant Activity against DPPH Free Radical. Antioxidants 2014, 3(2), 309-322; http://dx.doi.org/10.3390/antiox3020309.

[33] Abhishek Giri, Bhuwan B. Mishra, Priyanka Tripathi, Prahlad P. Agrawal and Pashupati P. Singh. Quantitative structure-activity relationship of matrix metalloproteinase inhibitors based on quantum chemical descriptors. Journal of Computational methods in Molecular Design, 2011, 1 (4):14-21.

[34] Omer Abdalla Ahmed Hamdi, El Hassane Anouar, Jamil A. Shilpi , Zuhra Bashir Khalifa Al Trabolsy,Sharifuddin Bin Md Zain, Nur Shahidatul Shida Zakaria, Mohd Zulkefeli, Jean-Frédéric F. Weber,Sri Nurestri A. Malek, Syarifah Nur Syed Abdul Rahman and Khalijah Awang. A Quantum Chemical and Statistical Study of Cytotoxic Activity of Compounds Isolated from Curcuma zedoaria. International Journal of Molecular Sciences. 2015, 16(5), 9450-9468; http://dx.doi.org/10.3390/ijms16059450.

[35] Qing Meng1, Ziyin Yang, Guoliang Jie1, Ying Gao, Xinghai Zhang, Wei Li, Bo Li1, Youying Tu1. Evaluation of Antioxidant Activity of Tea Polyphenols by a Quantum Chemistry Calculation Method PM6. Journal of Food and Nutrition Research, 2014, Vol. 2, No. 12, 965-972. http://dx.doi.org/10.12691/jfnr-2-12-17.

[36] Ammar A. Ibrahim and Eid A.A. alrazaq. Physical Properties of Phenol Compound: Semi-empirical Calculation of Substituent Effects [Part One]. American journal of applied sciences 6(7)13851389, 2009. American Journal of Applied Sciences http://dx.doi.org/10.3844/ajassp.2009.1385.1389.

[37] HyperChemTM, Release 7.5 Pro for Windows, "Molecular Modeling System", Hypercube, User Evaluation copy, Organization: Evaluation copy, Dealer: Copyright $@ 2002$ Hypercube,Inc, Serial No.99-999-9999999999.

[38] G.H. Wannier. The Threshold Law for Single Ionization of Atoms or Ions by Electrons. Physical Review Letters., 90, 817 (1953). http://dx.doi.org/10.1103/physrev.90.817.

[39] Mamoun S.M. Abd El Kareem. Mass Spectrometric Study Of Some FLUOROQUINOLONE Drugs Using Electron Ionization and Chemical Ionization Techniques In Combination with SemiEmpirical Calculations. Physics department, Faculty of Science, Benha University (2013) 